Revista de Ensino em Artes, Moda e Design

Dossiê 6

A modelagem integrada ao projeto de Moda no âmbito do ensio

\title{
MODA E ARTESANATO NA ESCOLA HELEN KELLER DE RIBEIRÃO PRETO- SP
}

\author{
Fashion and handbags at the Helen Keller de \\ Ribeirão Preto-SP school
}

\section{Moda bazares y artesanía en la escuela Helen Keller de Ribeirão Preto-SP}

\author{
Vitória Guessi ${ }^{1}$ \\ Juliana Bononi²
}

${ }^{1}$ Graduanda em Moda no Centro Universitário Moura Lacerda, membro do Grupo NIEPED (Núcleo Interáreas de Estudos e Pesquisas em Educação e Diversidade). Tem experiência na área de Vendas, Mídias Sociais e Produção de Moda. Ex-bolsista de Iniciação Científica - CUML (2018). Lattes: http://lattes.cnpq.br/9997407467188218. ORCID: https://orcid.org/0000-0001-9852-1194. E-mail vi.guessi@hotmail.com

2 Profa. Ma. Mestrado em Design de Produto. Pós-Graduada em Varejo de Moda e Graduada em Moda, docente de Modelagem e Tecnologia Têxtil nos cursos de Graduação em Moda do Centro Universitário Moura Lacerda e UNIFRAN, membro do Grupo NIEPED. Lattes: http://lattes.cnpq. br/3722965298519701. ORCID: https://orcid.org/0000-0003-4386-9649. E-mail julianabs9@gmail.com 


\section{Resumo}

O projeto "História, memória e cegueira: contribuições da Escola para Cegos Helen Keller (1954-1990) de Ribeirão Preto à educação", aprovado pela FAPESP nº 2017q23240-8, coordenado pela Profa. Dra. Daniela Leal e outros docentes do Centro Universitário Moura Lacerda, recebeu um grande acervo fotográfico, onde algumas imagens são de bazares realizados na década de 60, com produtos de moda e artesanato desenvolvidos pelos alunos da escola. O presente projeto de pesquisa exploratória descritiva e qualitativa, tem o objetivo de descrever os detalhes das fotos recebidas, relatando os trabalhos de moda e artesanato desenvolvidos, por meio de observação assistemática passiva, na intenção de trazer a luz essa parte da história de educação inclusiva de nossa cidade. Esse estudo trouxe a possibilidade de conhecer o universo do deficiente visual, em especial dos alunos da Escola Hellen Keller. Nas imagens foi possivel observar vários produtos desenvolvidos e comercializados como; roupas (entre saias, blusa e vestidos), bolsas, panos de prato, aventais, peças em crochê e tricô, bonecos e árvore decorativa para o natal, entre outros. A escola motivava as capacidades manuais na intenção de criar oportunidades, tanto para a busca do mercado de trabalho, quanto para a inclusão social, desde a década de 60. O levantamento bibliográfico bem como toda a pesquisa contribuiu para entender as pessoas com deficiência visual, sua forma de pensar, de agir e de se desenvolver, e que as mesmas têm capacidade para aprender e se tornar independentes, desde que thes sejam dadas oportunidades.

Palavras-chave: Moda; Artesanato; Fotografia; Deficiente Visual; Escola Hellen Keller.

\section{Abstract}

The project "History, memory and blindness: contributions from the School for the Blind Hellen Keller (1954-1990) from Ribeirão Preto to education", approved by FAPESP under number 2017q23240-8, coordinated by Prof. Dr. Daniela Leal and other professors from the University Center Moura Lacerda received a large photographic collection, in which some images are from bazaars and fairs held in the 1960s, carrying fashion products and handicrafts developed by the students of the school. The present research project has the objective of describing some details of the photos received, telling about the works developed, through exploratory descriptive and qualitative research, with the intention of bringing to light that part of history about inclusive education in our city. This study has brought about the possibility of knowing the universe of the visually impaired, especially the students from the Helen Keller School. In the images, it is possible to observe several products developed and marketed by the school, such as clothes (skirts, blouses, dresses), handbags, dish cloths, aprons, crocheted and knitted items, dolls, as well as decorated Christmas trees, among others. The school also motivated their students to develop manual skills in order to create opportunities, both for labor market as well as for social inclusion sin- 
ce the 1960s. The bibliographical survey and all this research contributed to understand visual handicapped people, their form of thinking, acting and developing skills, showing that those students have the capacity to learn and become independent, provided that opportunities are offered.

Keywords: Fashion; Crafts; Photography; Visually Handicapped People; Helen Keller School.

\section{Resumen}

El proyecto Historia, memoria y ceguera: aportes de la escuela para ciegos Helen Keller (1954-1990) de Ribeirão Preto a la educación, aprobado por FAPESP $n^{\circ}$ 2017q23240-8, coordinado por Profa. La Dra. Daniela Leal y otros maestros del Centro Universitario Moura Lacerda recibieron una gran colección fotográfica, donde algunas imágenes son de bazares hechos en los años 60, com productos de moda y artesanía desarrollados por los estudiantes de la escuela. Este proyecto de investigación tiene como objetivo describir los detalles de las fotos recibidas, infor-mando el trabajo desarrollado a través de una investigación exploratória descriptiva y cualitativa, con la intención de sacar a la luz esta parte de la historia de la educación inclusiva en nuestra ciudad. Este estudio trajo la posibilidad de conocer el universo de los discapacitados visuales, especialmente los estudiantes de la Escuela Hellen Keller. En las imágenes fue posible observar varios productos desarrollados y comercializados como ropa (faldas, blusas, vestidos), bolsos, paños de cocina, delantales, piezas de ganchillo y tejido de punto, muñecas y árboles de navidad, entre otros. La escuela motivó las habilidades manuales en la intención de crear oportunidades, tanto para la búsqueda del mercado laboral como para la inclusión social, desde los años 60. La encuesta bibliográfica y toda la investigación contribuyeron a comprender a los discapacitados visuales, su forma de pensar, actuar y desarrollarse, y que tienem la capacidad de aprender y ser independiente, siempre que se le brinde la oportunidad.

Palabras-clave: Moda; Manualidades; Fotografía; Deficiente visual; Escuela Hellen Keller.

\section{INTRODUÇÃO}

Observa-se que a sociedade passou a enxergar as dificuldades impostas à vida dos deficientes e sinaliza com mudanças favoráveis na tentativa de adaptar- se à realidade deles, ao criar oportunidades para uma melhor qualidade de vida no trabalho, no lazer e nos estudos.

O vestuário, assim como os espaços urbanos e os meios de transportes, também devem contribuir para maior independência e praticidade. $O$ design e suas várias frentes de estudo e projeto consistem em ferramenta importante no processo de 
inclusão de pessoas com deficiência, e, em particular, do deficiente visual, o qual, ao longo da história atual do Brasil vem desenvolvendo muitas atividades artesanais, tais como o trabalho artesanal com jornais e revistas, a pintura de telas, entre outros.

O projeto "História, Memória e Cegueira: contribuições da Escola para Cegos Hellen Keller (1954-1990) de Ribeirão Preto à educação", coordenado pela Profa. Dra. Daniela Leal e outros docentes do Centro Universitário Moura Lacerda, recebeu um grande acervo fotográfico, no qual se podem ver algumas imagens de bazares realizados na década de 60 , com produtos de moda e artesanato desenvolvidos pelos alunos da escola. Com esse material em mãos, verificou-se a necessidade de descrever cada detalhe das fotos recebidas, com relatos sobre os trabalhos desenvolvidos por meio de observação assistemática passiva. Para tanto, foi desenvolvida uma pesquisa exploratória, descritiva e qualitativa, com a intenção de trazer à luz essa parte da história de educação inclusiva de nossa cidade.

\section{A ESCOLA HELEN KELLER E O PROJETO NIEPED}

A escola, fundada em 1954, tinha como objetivo preparar os alunos para completarem seus estudos em unidades de ensino regulares, no município e na região de Ribeirão Preto. Inicialmente funcionou com duas salas de aula nas dependências da Escola SENAC, sendo uma delas para alfabetização, e a outra para trabalhos manuais.

O NIEPED, Núcleo Interáreas de Estudos e Pesquisas em Educação e Diversidade, é formado por docentes do Centro Universitário Moura Lacerda, de Ribeirão Preto, que atualmente desenvolve o projeto intitulado "História, Memória e Cegueira: contribuições da Escola para Cegos "Helen Keller" de Ribeirão Preto (1954-1990) à Educação", coordenado por Daniela Leal, Professora Doutora do Mestrado do Centro Universitário Moura Lacerda, em parceria com coordenadores, professores e alunos dos cursos de Publicidade e Propaganda, Pedagogia, Letras e Moda da mesma instituição, um projeto de pesquisa que visa resgatar a história e a pedagogia utilizada na Escola para Cegos "Helen Keller".

O grupo recebeu dos familiares do idealizador da escola, Professor José Ferreira Martins Júnior, um grande acervo de fotografias, algumas com descrição de datas e lugares dos bazares realizados com produtos confeccionados pelos alunos na década de 60.

\section{REFERENCIALTEÓRICO}

Primeiramente, foi realizado um levantamento bibliográfico, de modo a estabelecer os parâmetros da pesquisa por meio de estudos realizados por outros pesquisadores.

Para Lima et al. (2013), o termo deficiência visual refere-se à diminuição da resposta visual, que pode ser leve, moderada, severa, ou profunda. Acomete um grupo de pessoas com visão subnormal ou indivíduos com baixa visão; ou ainda, pessoas em que há a ausência total da resposta visual, isto é, portadores de cegueira. 
Segundo Cunha et al (2011), os indivíduos com cegueira são aqueles em que a visão é nula ou diminuída, a ponto de incapacitá-los para o exercício da maioria das tarefas diárias. Por sua vez, os indivíduos com baixa visão são aqueles que apresentam acuidade visual de 0,25 a 0,02 no melhor olho, após correção máxima. Existem ainda os indivíduos com restrição do campo visual, ou visão em túnel, que, independentemente da acuidade visual que possuem, também são considerados cegos, já que qualquer visão nesta amplitude impede a apreensão do ambiente de forma ampla e irrestrita, contribui Cunha et al (2011).

O indivíduo que perdeu a visão precisa de acompanhamento familiar e psicológico, pois a cegueira causa um grande impacto na vida da pessoa, e suas consequências são potencialmente danosas e até irreversíveis. Para Oliveira et al. (2002), a ausência da modalidade visual exige experiências alternativas de desenvolvimento a fim de cultivar a inteligência e promover capacidades socioadaptativas. $O$ ponto central desses esforços é a exploração do pleno desenvolvimento tátil. Os autores afirmam, ainda, que a modalidade tátil se desenvolve por um processo de crescimento gradual e sequencial, levando a deficiência visual (DV) de um reconhecimento simplista a uma interpretação complexa do ambiente. Os pais e educadores têm um papel importantíssimo neste processo, pois podem estimular o desenvolvimento desses indivíduos desde a infância. Mais ainda, como responsáveis por crianças cegas, eles devem estimular os sentidos durante toda a vida dessas pessoas, já que essa é a base para os níveis mais altos do desenvolvimento cognitivo.

Monte Alegre (2003) realizou uma pesquisa, na qual estudou as representações que professores de crianças cegas tinham sobre seus alunos. Seis professoras foram entrevistadas, divididas em três grupos: duas professoras de sala comum sem apoio especializado; duas professoras de sala comum em escola com sala de recursos; duas professoras especializadas de sala de recursos.

O autor supracitado constatou que a linguagem oral é prioritariamente utilizada pelos docentes, principalmente em situações de falta de recursos materiais e de qualificação profissional para lidar com a deficiência visual. Ele verificou, ainda, o desconhecimento sobre os materiais adaptados para o cego (inclusive o braile), por parte dos professores de salas comuns, além da não comunicação entre professores das salas regulares e de recursos. O autor concluiu que, além de melhores condições educacionais para esses alunos, faz-se necessária a preparação dos professores das salas comuns, com base em: "As dúvidas sobre quais são as necessidades cognitivas de um aluno cego, (que) foram expressas realçadamente" (p. 281).

Ormelezi (2000) fez outro estudo interessante, no qual investigou a aquisição de representações mentais - imagens e conceitos - pelo cego. Foram entrevistados cinco adultos, com idades entre 19 e 44 anos. Foi constatado que a formação de imagens e conceitos de todos os participantes se dá pela experiência tátil, auditiva e olfativa. A autora concluiu que as entrevistas mostraram a importância de se estudar o cego a partir de seu próprio referencial, evitando-se partir de uma abordagem de videntes. Para os pais, os profissionais e as instituições em geral, a impossibilidade do ver confunde-se com a impossibilidade do existir, do aprender, do comunicar-se, do relacionar-se, do fazer parte, de entrar para a cultura e tornar-se sujeito (ORMELEZI, 2006, p. 176). 
Nunes e Lomônaco (2008) propuseram para três crianças cegas, com idades entre 9 e 10 anos, o ensino de quatro grupos de conceitos: coisas tateáveis pequenas, coisas tateáveis grandes, conceitos não-tateáveis, e conceitos abstratos. Os resultados indicaram que todos os participantes apresentaram desempenho apreciavelmente melhor após a intervenção. Com essa pesquisa foi possível constatar que a falta ou redução da visão não é o principal obstáculo para a inclusão dos deficientes visuais como cidadãos, plenos de direitos e deveres.

Caso lhes sejam oferecidas as condições de aprendizado e os meios de desenvolver e aplicar suas habilidades, os DV têm condições de andar sozinhos, estudar, trabalhar e participar da vida socioeconômica, cultural e política da sociedade. Cabe, ainda, observar que as pesquisas apresentadas são em sua maioria atuais, apresentando as falhas e a falta de preparo tanto dos professores como da sociedade na inclusão do DV. Já a Escola Helen Keller, de Ribeirão Preto, desenvolvia esse trabalho desde a década de 60.

\subsection{Inclusão, Moda e Deficiência Visual}

A inclusão social deve ser entendida como o compartilhamento de recursos e ambientes acessíveis por todos, e este é o pensamento com relação às pessoas com deficiência, seja com problemas de mobilidade reduzida, ou orientação direcional, entre outros. Para o desenvolvimento de bons produtos voltados à área do design inclusivo, é possível dizer que apenas pesquisas teóricas e embasamentos técnicos não resultarão em produtos de grande sucesso.

Sassaki (1997) defende que a sociedade precisa se adaptar às necessidades da pessoa com deficiência. Entendemos que esse é o ponto de partida para que haja inclusão, para que a pessoa com deficiência possa se desenvolver nos diferentes aspectos de sua vida.

Ferreira e Morellato (2012) afirmam que a deficiência "advém da interação entre corpos comprometidos e ambientes excludentes". E, muitas vezes, é este ambiente excludente que exacerba a condição de "sentir-se deficiente" do cego, através de um enfraquecimento moral que vem desta incapacidade de realizar certas tarefas. "As pesquisas mais recentes atestam que os olhos são responsáveis por no mínimo $80 \%$ das impressões recebidas através da sensibilidade. Habitamos um mundo que se manifesta de forma predominantemente visual" (Oliveira, 1998). Essa perspectiva tem implicações diretas no design, evidenciada na seguinte citação de MUNARI (1998):

Muitos designers projetam ainda hoje apenas para o sentido da visão. Preocupam-se unicamente em produzir algo belo de se ver e não lhes interessa que o objeto resulte depois desagradável ao tato, se não tem relações formais com a anatomia humana [...], ou então não se importam de usar materiais que impedem o corpo de transpirar como acontece com algumas cadeiras e poltronas [...] que apesar de muito bonitas são desconfortáveis (MUNARI, 1998, p. 373).

Após tantos anos das afirmações de Oliveira (1998) e Munari (1998), Maximiliano e Tomasulo (2013), reiteram que, em nossa sociedade, muitas pessoas são extrema- 
mente visuais, e atribuem esse fato aos indícios da importância dada em relação à aparência e a características visuais que se despertam nas pessoas, o que contribuiu para o aumento do mercado da beleza nos últimos anos.

No universo da moda não seria diferente, pois é um mercado que cresce num ritmo significativo, com novas tendências, temáticas, cores, tecidos e modelagens que despertam interesse e desejo em consumidores do mundo inteiro. A moda possui forte apelo visual para aqueles que a desenvolvem, e, mais ainda, para os que a consomem; porém, uma peça de roupa não é somente algo visual; ela pode trazer experiências sensoriais que estimulam outros sentidos, adquiridos por meio do toque que determinados tecidos proporcionam, contribuem Maximiliano e Tomasulo (2013)

Os profissionais que atuam na educação, na habilitação e na reabilitação de escolares com baixa visão necessitam conhecer tal população, porque quanto maior o conhecimento, melhor será a elaboração de um programa de habilitação e/ou reabilitação visual, propiciando desenvolvimento, transmissão de conhecimentos de acordo com as necessidades de cada um, transformação em novos saberes, aprendizagem e preparo para a inclusão social (FERRONI; GASPARETTO, 2012).

Bononi e Domiciano (2018) procuraram verificar, por meio de questionários, como pais e professores de crianças com deficiência visual estão trabalhando o estímulo tátil por meio do vestuário. Uma vez que podem aprender noções de formas e volumes, diferenciação do liso, do áspero e do macio, do duro e do mole, do quente e do frio. Entre outras qualidades, podemos destacar, principalmente, o uso da sensibilidade na construção das sensações de conforto e desconforto, assim como a independência e o prazer em se vestir, além da interação com o próprio vestuário, com os pais, professores e, principalmente, com outras crianças. De acordo com as respostas, mesmo afirmando que sabem e acreditam que o vestuário pode ser educativo e estimular a experiência tátil, eles não estimulam as crianças nesse sentido. Mas a principal constatação foi que as próprias educadoras não exploram o potencial da experiência tátil por meio do vestuário, e, por esse motivo, nunca orientaram os pais acerca disso. Deixando de trabalhar a independência, e de desenvolver a autoconfiança através de experiências enriquecedoras por meio da manipulação e experimentação de objetos reais presentes no cotidiano de todos, contribuem Bononi e Domiciano (2018).

Diante desses dados, verifica-se que o design e várias de suas frentes de estudo e projeto consistem de ferramentas importantes no processo de inclusão de deficientes de várias naturezas, e, em particular, do deficiente visual.

\section{DESCRIÇÃO DAS FOTOS}

Foram escolhidas 7 fotografias em preto e branco, seguindo o critério das que possuíam maior número de produtos comercializados nos bazares. As descrições foram baseadas na observação assistemática passiva, de acordo com os artefatos expostos, não foi possível encontrar as pessoas que aparecem, já que muitas faleceram, ou são de outras cidades da região. 
Figura 1: Exposição-Feira em Sertãozinho na década de 1960.

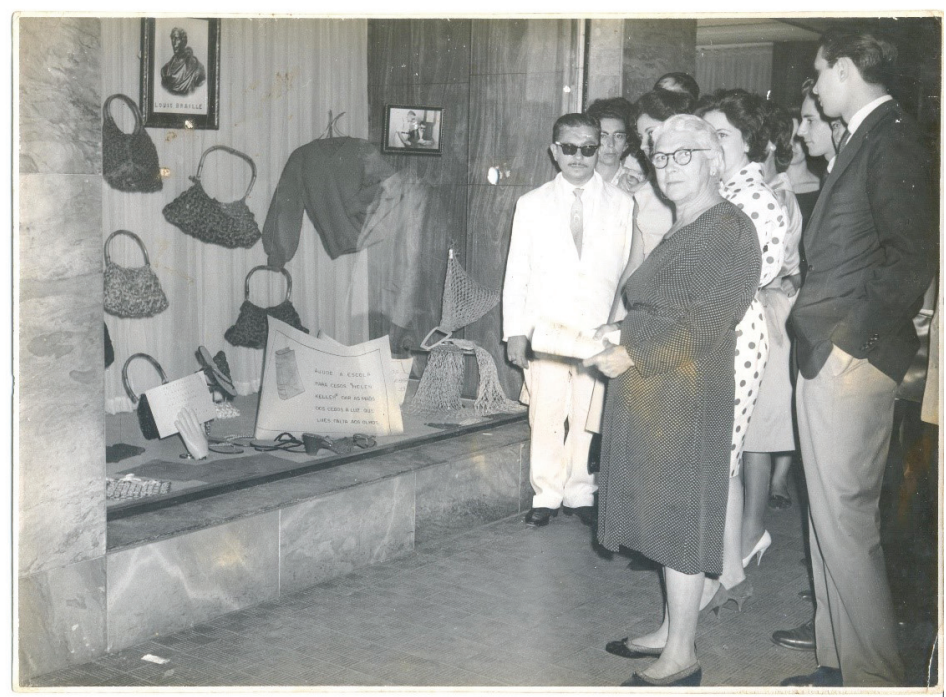

Fonte: Arquivo NIEPED

As figuras 1, 2, e 3 são de uma Exposição-Feira, realizada na Rua Barão do Rio Branco, número 475, na cidade de Sertãozinho/SP, localizada a $25 \mathrm{~km}$ de Ribeirão Preto/SP, no dia 29 de setembro de 1960. São 4 fotos em ângulos diferentes.

$\mathrm{Na}$ figura 1 é possível visualizar alguns dos produtos que foram desenvolvidos pelos alunos da Escola Hellen Keller de Ribeirão Preto/SP, como: acessórios, bolsas de crochê, sapatos, blusas de tricô, porta-retratos, cartazes e luvas.

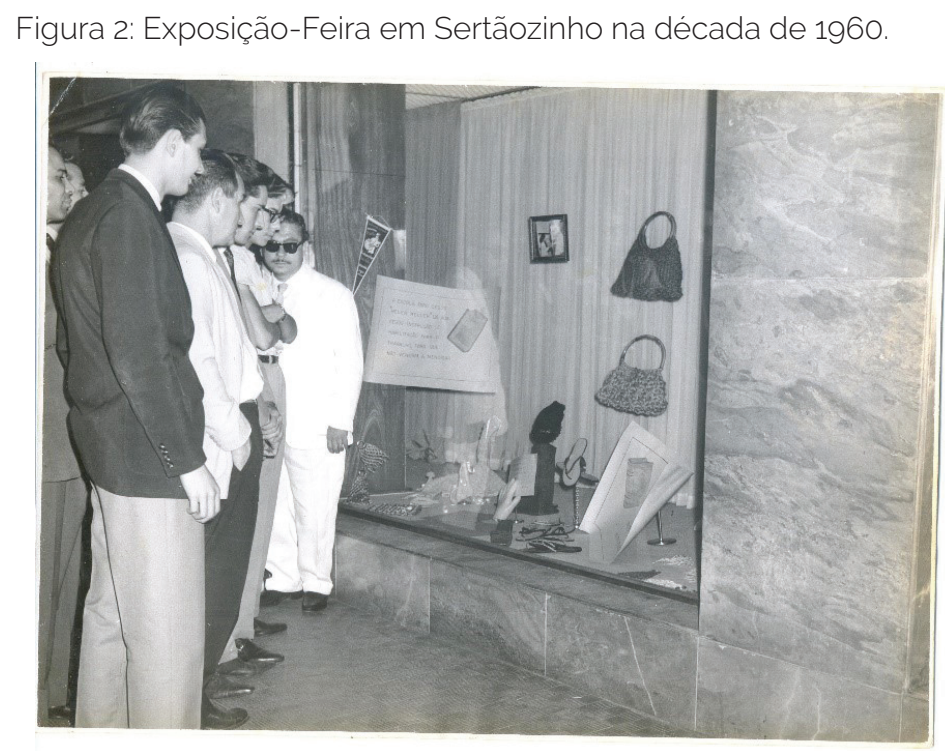

Fonte: Arquivo NIEPED

As figuras 1, 2, e 3 são de uma Exposição-Feira, realizada na Rua Barão do Rio Branco, número 475, na cidade de Sertãozinho/SP, localizada a $25 \mathrm{~km}$ de Ribeirão Preto/SP, no dia 29 de setembro de 1960. São 4 fotos em ângulos diferente

A figura 2 retrata a mesma Exposição-Feira da figura 1, porém é possível ver outros detalhes expostos em uma mesma vitrine. 
Figura 3: Exposição-Feira em Sertãozinho na década de 1960.

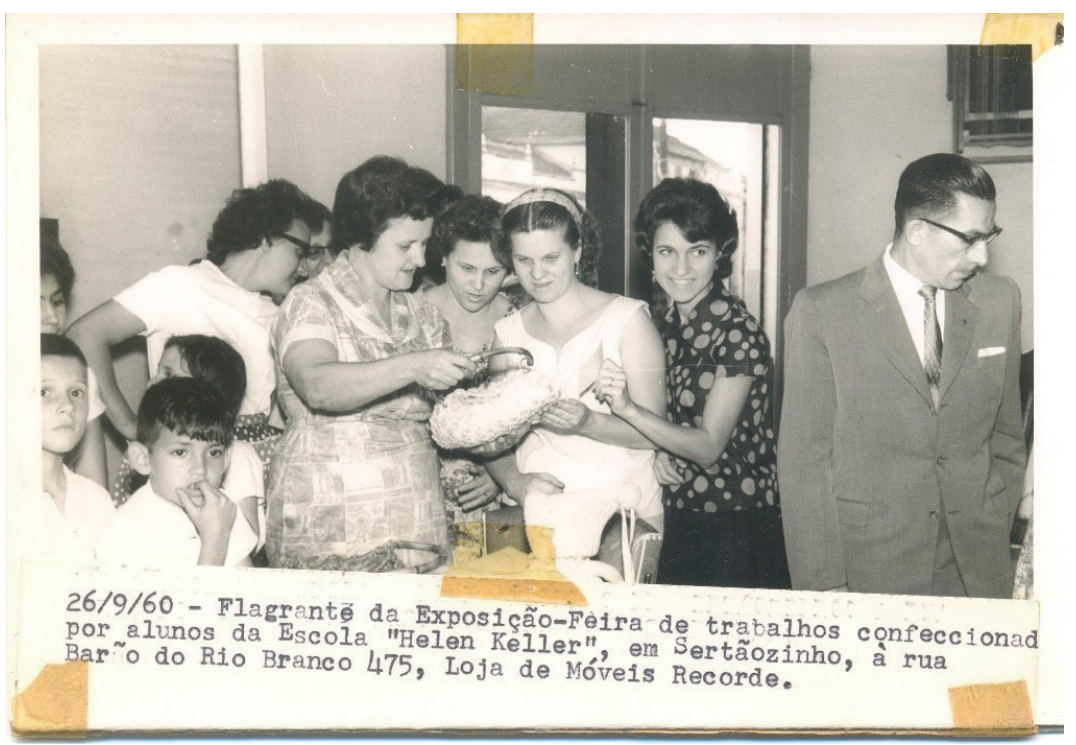

Fonte: Arquivo NIEPED

As figura 1, 2, e 3 são de uma Exposição-Feira, realizada na Rua Barão do Rio Branco, número 475, na cidade de Sertãozinho/SP, localizada a $25 \mathrm{~km}$ de Ribeirão Preto/SP, no dia 29 de setembro de 1960. São 4 fotos em ângulos diferentes.

Na figura 3, também da Exposição-Feira, pode-se visualizar o deslumbramento das mulheres da foto diante da bolsa desenvolvida pelos alunos da Escola.

Figura 4: Exposição-Feira em Sertãozinho na década de 1960

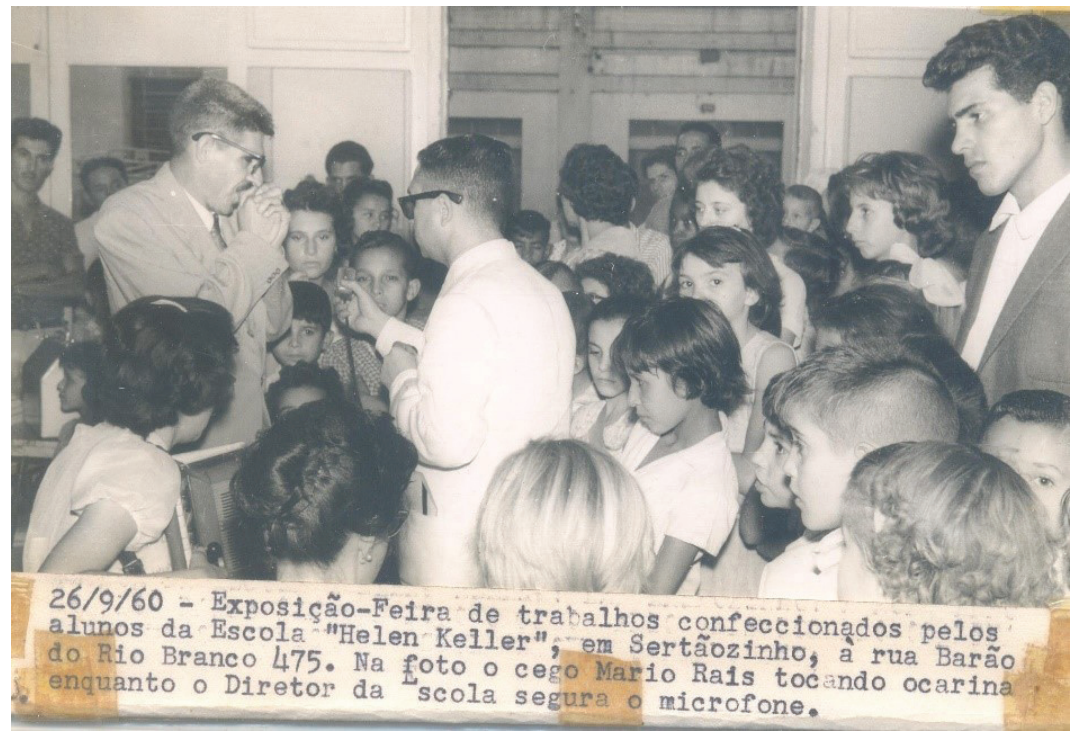

Fonte: Arquivo NIEPED

A figura 4 apresenta Mario Rais, uma pessoa com deficiência visual, tocando ocarina - um instrumento de sopro, enquanto o Diretor da Escola, Professor José Ferreira Martins Júnior, segura o microfone. À sua volta, várias crianças e também alguns adultos, apreciando este momento. 
Figura 5: Exposição Galeria Paulista de Moda 1961

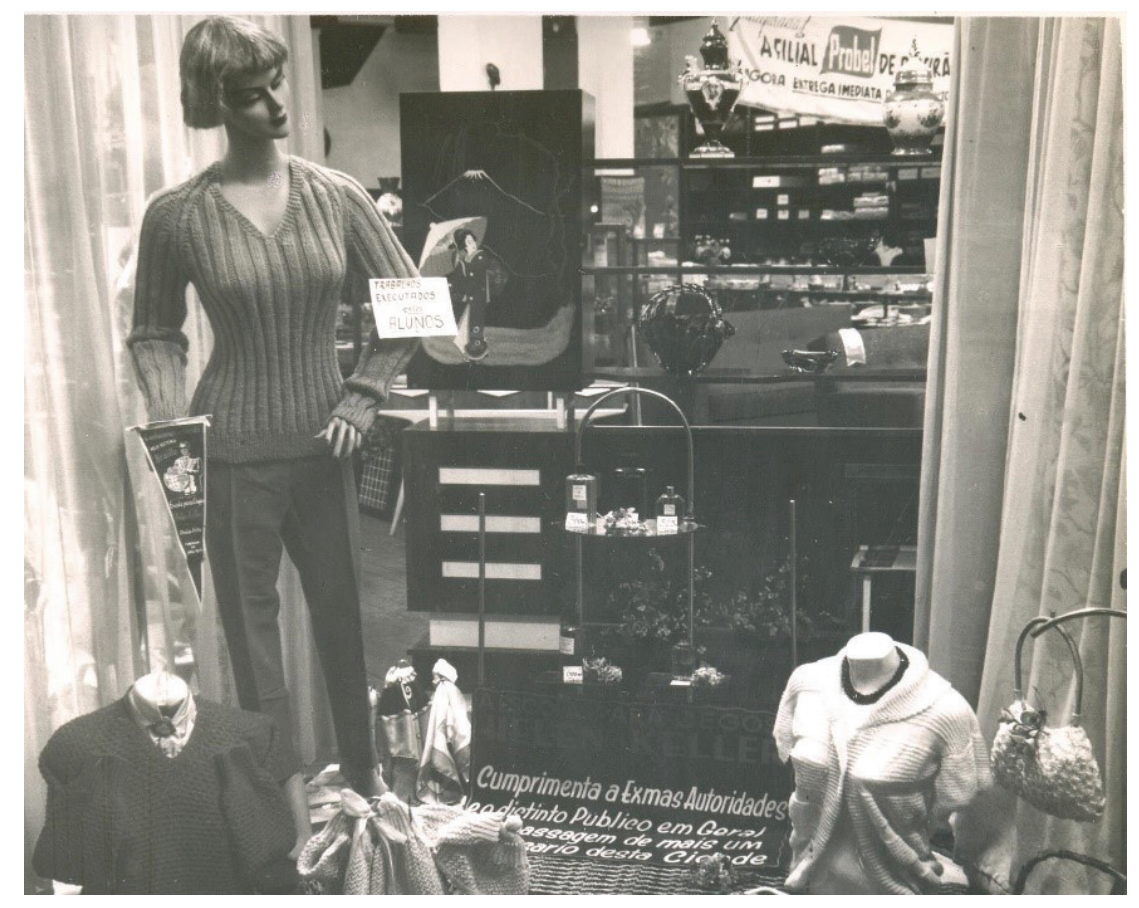

Fonte: Arquivo NIEPED

A figura 5 traz uma variedade de produtos artesanais que foram expostos na Galeria Paulista de Moda, em 1961. Dentre eles, acessórios como colares, bolsas, blusa em tricô, capa de botijão de gás de crochê, aventais em tecido, e tapetes em patchwork.

Figura 6: Bazar em Sertãozinho/SP em 1962.

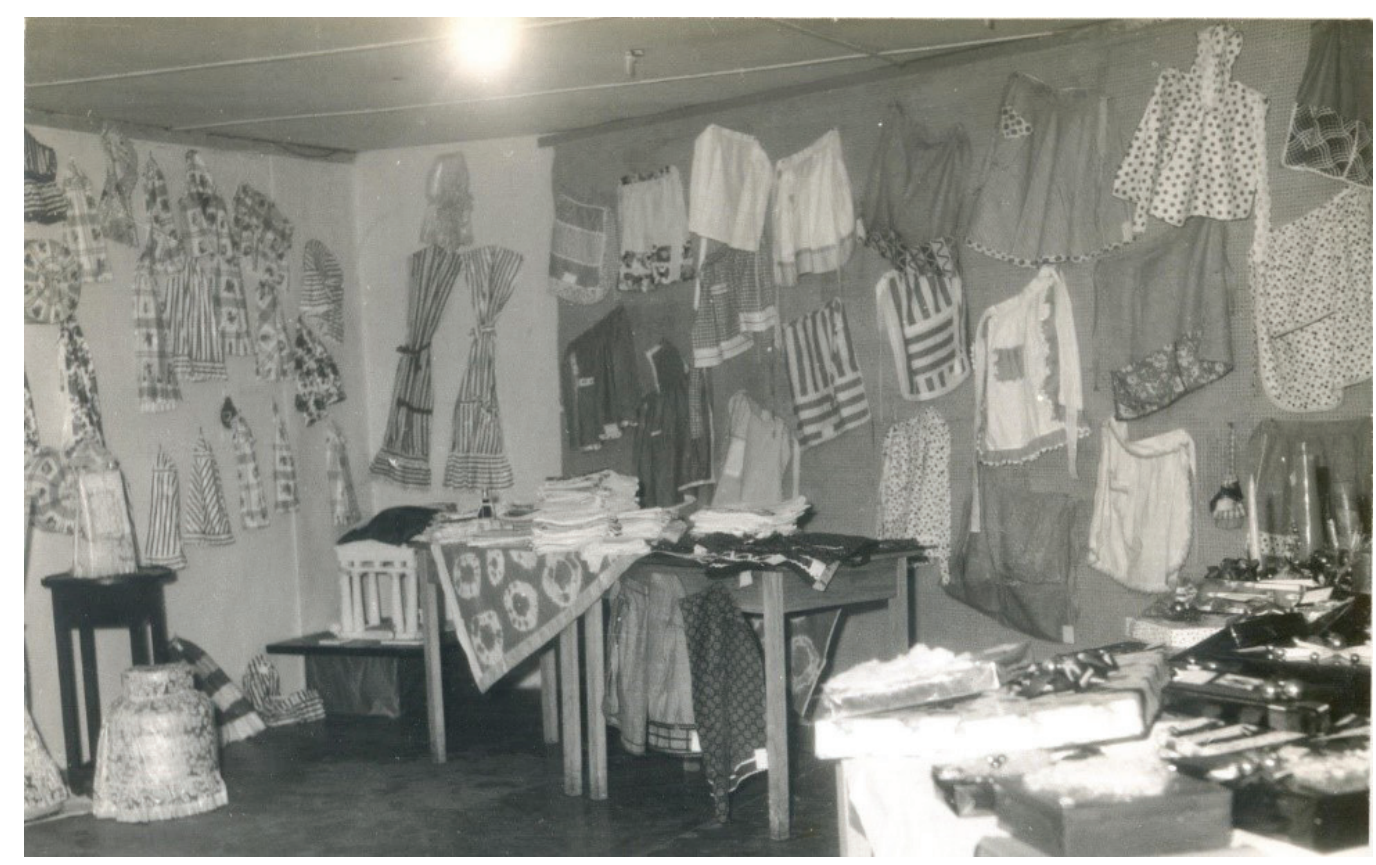

Fonte: Arquivo NIEPED 
Figura 7: Bazar em 1962.

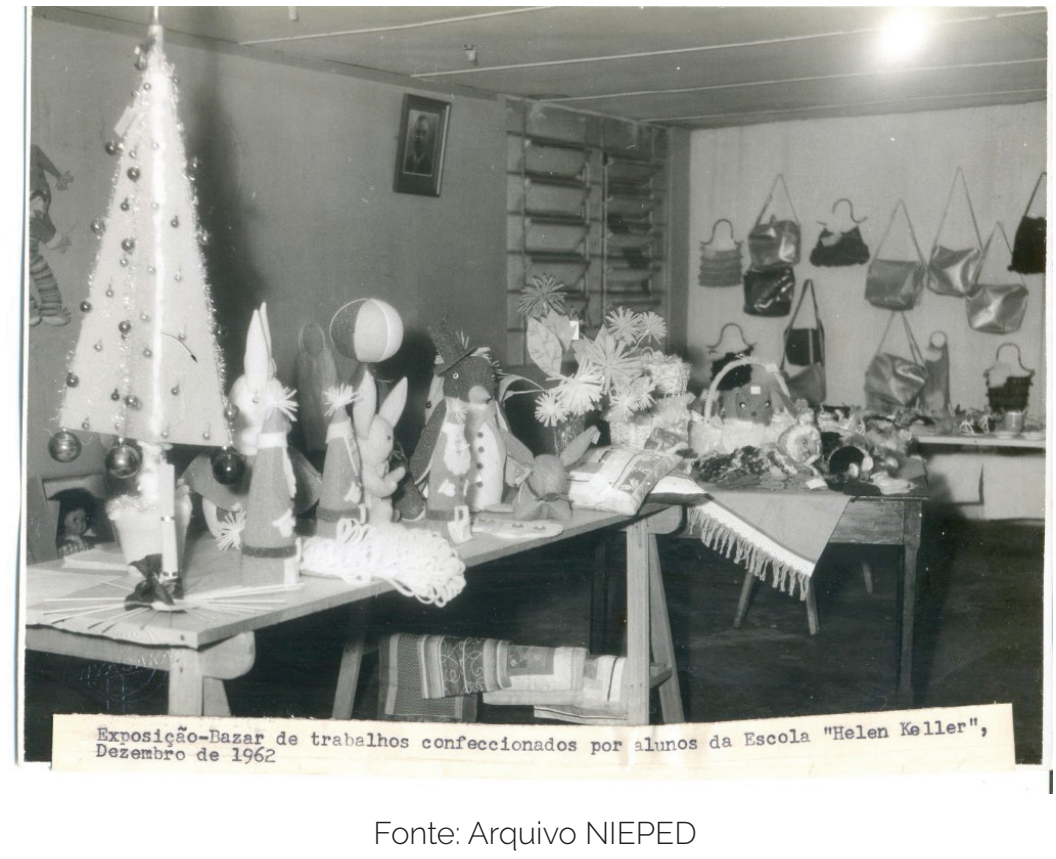

Assim como a figura 6, a foto 7 também é do bazar realizado em 1962, nas quais podemos observar peças decorativas para o Natal, bonecos de pano, como foca e pinguim. Nestas fotos estão visíveis todos os trabalhos artesanais e as confecções desenvolvidas pelos alunos da Escola. Todos estes produtos eram vendidos em Ribeirão Preto/SP e região.

A Escola contava com uma professora de artesanato, que atualmente reside na cidade de Franca/SP. Algumas das alunas, que também possuíam habilidade para fazer crochê e tricô, ajudavam durante as aulas e na produção. Atualmente, a cidade de Sertãozinho/SP conta com uma escola para cegos, mas não há ninguém lá atualmente que tenha participado desses bazares.

\section{RESULTADO DA PESQUISA}

A cegueira é uma deficiência visual que se caracteriza pela falta de possibilidades de apreender as informações do mundo por meio da visão, segundo dois tipos: cegueira e baixa visão. A cegueira congênita ocorre quando a perda da visão ocorre antes dos cinco anos. A partir dessa idade, os atingidos são chamados de cegos adventícios - quando a cegueira acontece inesperada e imprevisivelmente.

Apesar da premissa de que a visão é o sentido mais importante, e mesmo que haja uma limitação causada pela deficiência, uma vez que estejam adaptadas, tendo passado por processos de aprendizagem, as pessoas com deficiência visual têm várias possibilidades de conhecer o mundo em que vivem, inclusive por meio dos outros sentidos.

A percepção espacial pelo cego se dá pela união de sensações táteis, cinestésicas (olfato, gustação, sistema cinestésico) e auditivas, todas aliadas às experiências mentais que vive o sujeito. Logo, percebe-se que a falta de visão impõe diferentes caminhos. Todavia, isso não impede o desenvolvimento, pois existe a capacidade de 
se desenvolver como todas as pessoas, desde que the sejam dadas as condições adequadas para tal.

O modo de aprendizagem do aluno cego gera muitas preocupações, uma vez que os objetos, eventos, instituições e costumes a serem conceituados estão sempre mudando, se levarmos em consideração uma sociedade tecnológica como a atual.

Portanto, ao longo do curso da vida, os processos de aquisição adquirem formas cada vez mais individualizadas e adaptadas a pessoas e grupos. A questão da aquisição de conceitos por cegos passa por tudo aquilo que se refere à aquisição de conceitos por todas as pessoas, tendo elas ou não alterações sensoriais.

O uso do tato como recurso de ensino para os cegos permite captar as propriedades dos objetos, tais como textura, temperatura e forma. Tal captação ou percepção funciona a curtas distâncias, correspondendo ao alcance da mão. Mas é distinta da visão, que permite a obtenção de informação simultânea e à distância. Por fim, o tato é um recurso valioso para o ensino de alunos cegos. Entretanto, ele não pode ser visto como um substituto da visão, nem pensado de forma independente.

Para entrar em contato com o deficiente, saber sobre ele e sobre sua percepção, a fim de guiá-lo educacionalmente, é necessário procurar entender seu estilo de explorar os objetos, e sua maneira de usar o seu corpo para isso, buscando o sentido que o objeto tem para ele, em sua relação com as pessoas e coisas em diferentes situações.

Para saber das pessoas com deficiência visual, é preciso voltar-se para seu mundo vivido, buscando recuperar o nascimento do sentido e descrever a totalidade do que aparece em cada situação - seus gestos, os modos de dizer e de agir.

Já para compreendê-la, é preciso ter atenção aos seus diferentes modos de ser e às mudanças de suas concepções. A pessoa com deficiência visual precisa dispor de condições para explorar, de forma a organizar o mundo ao seu redor e nele se situar. E diante de todas as situações educacionais, é preciso usar o mais possível todas as suas possibilidades táteis, térmicas, olfativas e auditivas.

\section{CONSIDERAÇÕES FINAIS}

A falta de visão impõe diferentes caminhos, mas não impede o desenvolvimento, pois existe no deficiente visual a capacidade para se desenvolver como qualquer outra pessoa, desde que the sejam dadas as condições adequadas para tal, já que a adaptação ao ambiente e a estimulação para tal ficam prejudicadas caso não exista o reconhecimento do potencial de cada indivíduo.

É por essas razões que a história da Escola Helen Keller é relevante e fundamental. Ela buscou ser não ser apenas uma instituição assistencialista, mas também procurou ensinar às pessoas com deficiência visual, levando ao desenvolvimento de todas as suas capacidades, e fazendo-as descobrir diferentes horizontes, tais como o trabalho artesanal e a costura.

Nas imagens podemos observar produtos desenvolvidos pelos alunos - tais como roupas (saias, blusas e vestidos), bolsas, panos de cozinha, aventais, peças fei- 
tas em crochê e tricô, bonecos e árvores decorativas para o Natal, entre outros.

A Escola incentivava as capacidades manuais com a intenção de criar oportunidades, tanto para a busca do mercado de trabalho, quanto para a inclusão social, visto que esses produtos eram vendidos em bazares durante o período da década de 60. O desenvolvimento de tal projeto trouxe, portanto, a possibilidade de conhecimento não apenas quanto ao universo do deficiente visual, mas, em especial, dos alunos da Escola Helen Keller de Ribeirão Preto/SP.

Todo o levantamento bibliográfico realizado, bem como a pesquisa, deram grande contribuição, sem dúvida, para uma melhor compreensão das pessoas com deficiência visual, suas formas de pensar e de agir e, ao mesmo tempo, de se desenvolver, provando que elas possuem capacidade para aprender e para se tornarem independentes, desde que lhes seja dada a oportunidade.

Além disso, observar e descrever essas fotos, além de conhecer os trabalhos feitos pelos alunos, foi como um mergulho no passado, de forma a entender mais sobre o tema da inclusão social, assim como aprender sobre a nossa cidade. ${ }^{1}$

\section{REFERÊNCIAS}

AMIRALIAN, Maria Lúcia T. M. Compreendendo o cego: uma visão psicanalítica da cegueira por meio de Desenho-Estórias. São Paulo: Casa do Psicólogo, 1997.

BONONI, J.; DOMICIANO, C. L. C. O uso do vestuário infantil como elemento de estímulo para o desenvolvimento tátil de crianças com deficiência visual: o papel dos pais e educadores. Revista ENSINARMODE, Florianópolis, Ano 1, N. 3, Junho-Setembro 2018, p. 153-169. DOI: http://dx.doi.org/10.5965/25944630312018151171 | ISSN 2594-4630.

BRITO, Inayê J. Gomes de, et al. O design de moda como inclusão social de portadores de deficiência visual. Revista Eletrônica de Educação e Tecnologia do SENAI-SP.

ISSN 1981-8270. v. 4, n. 9, out. 2010. Disponível em: http://revistaeletronica.sp.senai. br/index.php/seer/article/viewFile/154/98. Acessado em: 10/11/2014.

CUNHA, Ana Cristina Barros da; ENUMO, Sônia Regina Fiorim; CANAL, Cláudia Patrocínio Pedroza. Avaliação cognitiva psicométrica e assistida de crianças com baixa visão moderada. Paidéia (Ribeirão Preto). v. 21 - Edição: 48 páginas.

http://www.scielo.br/scielo.php?script=sci_arttext\&amp; pid=S 0103-863X2011000100005. Acessado em: 11/11/2014.

Estadão. Jornal do Estado de São Paulo online. Disponível em:

http://sao-paulo.estadao.com.br/noticias/geral,etiqueta-em-braile-deixa-moda-mais-acessivel-imp-668553. Acessado em: 04/01/2015.

${ }^{1}$ Revisão de Liani Fernandes de Moraes, Graduada em Letras Português e Inglês, e-mail vi.guessi@ hotmail.com 
FERREIRA, Francirosy Campos Barbosa; MORELLATO, Alice. Ser, sentir-se e viver com a cegueira e a estigmatizarão. Disponível em: file:///C:/Users/Julyka/Downloads/pontourbe-1092-11-ser-sentir-se-e-viver-com-a-cegueira-e-a-estigmatizacao. pdf. Acessado em: 28/12/2014.

FERRONI, Marília C. Câmara; GASPARETTO, Maria Elisabete Rodrigues Freire. Escolares com baixa visão: percepção sobre as dificuldades visuais, opinião sobre as relações com a comunidade escolar e o uso de recursos de tecnologia assistiva nas atividades cotidianas. Rev. bras. educ. espec., Marília, v. 18, n. 2, jun. 2012. Disponível em: http://www.scielo.br/scielo.php?script=sciarttext\&amp; pid=S1413-538201200 0200009\&amp;lng=pt\&amp;nrm=isso. Acessado em: 14/12/2014.

IBGE. Censo Demográfico 2010. Disponível em: http://biblioteca.ibge.gov.br/visualizacao/periodicos/94/cd2010religiãodeficiencia.pdf. Acessado em: 20/12/2014.

LIMA, Ana C. E.; FERREIRA; Jeniffer Cristiane; SILVA, Rômulo Gonçalves da. Deficiência visual: vida independente e inclusão. Disponível em: http://www.faeterj-caxias. net/revista/index.php/edutec/article/view/42. Acessado em: 20/12/2014.

LIMA JÚNIOR, Geraldo Coelho. Design de Moda e Percepção Tátil. Disponível em: http://www.coloquiomoda.com.br/anais/anais/2-Coloquio-de-Moda_2006/artigos/49.pdf. Acessado em: 28/12/2014.

MAXIMILIANO, Cristiani; TOMASULO, Simone Batista. O ensino de moda e a inclusão de deficientes visuais. E-Tech: Tecnologias para Competitividade Industrial, Florianópolis, v. 7, n. 2, p. 135-164, 2013.

MONTAGU, Asheley. Tocar: o significado humano da pele. São Paulo: Summus Editorial, 1986. Trad. Maria Silvia Mourão Netto.

MONTE ALEGRE, P. A. C. A cegueira e a visão do pensamento. Dissertação de Mestrado. Instituto de Psicologia, Universidade de São Paulo, São Paulo, 2003.

MUNARI, Bruno. Das coisas nascem coisas. São Paulo: Martins Fontes, 1998.

NUNES, Sylvia da Silveira; LOMÔNACO, José Fernando Bitencourt. Desenvolvimento de conceitos em cegos congênitos: caminhos de aquisição do conhecimento. Psicologia Escolar e Educacional, v. 12, n. 1, enero-junio, 2008, p. 119-138. Associação Brasileira de Psicologia Escolar e Educacional - Paraná, Brasil.

NEVES, Manuela; BARRETO, Marise; NEVES, Jorge. Design de uma etiqueta para pessoas com deficiência visual. VI CIPED, 2011. Disponível em: https://repositorium. sdum.uminho.pt/bitstream/1822/15745/1/Artigo\%20Etiqueta.pdf. Acessado em: 20/12/2014. 
OLIVEIRA, Fátima I. W. de. BIZ, Vanessa Aparecida; FREIRE, Maísa. Processo de inclusão de alunos deficientes visuais na rede regular de ensino: confecção e utilização de recur -sos recursos didáticos adaptados. Disponível em: https://scholar. google.com.br/scholar?bav=on.2,or.r_cp.r_qf.\&amp;bvm=bv.82001339,d.eXY\&amp;biw=1366\&amp;bih=667\&amp;dpr=1\&amp;um=1\&amp;ie=UTF-8\&amp;lr\&amp;$q=$ related tAXhb5pGuMB27M:scholar.google.com/. Acessado em: 20/12/2014.

OLIVEIRA, J. V. G.. Arte e visualidade: a questão da cegueira. Revista Benjamin Constant, 1998, 4(10), 7-10.

OLIVEIRA, M. B.; OLIVEIRA, M. K. (Orgs.). Investigações cognitivas: conceitos, linguagem e cultura. Porto Alegre: Artmed, 1999.

ORMELEZI, E. M. Inclusão educacional e escolar da criança cega congênita com problemas na constituição subjetiva e no desenvolvimento global: uma leitura psicanalítica em estudo de caso. Tese de doutorado. Faculdade de Educação, Universidade de São Paulo, São Paulo, 2006.

RESENDE, Cláudia Arantes Pires Di Guimarães; MACHADO, Janine Brito; SOUTO, Keila Cristina Dias; VIEIRA, Sandra da Silva; MARTINS, Eliecília F. Estudo sobre as vestimentas para deficientes visuais. Disponível em: http://www.coloquiomoda.com. br/anais/anais/7-Coloquio-deModa_2011/GT13/Poster/P_89620. A relacao_do_Deficiente_Visual_com_as_vestimentas.pdf. Acessado em: 20/12/2014.

SASSAKI, Romeu Kazumi. Inclusão: construindo uma sociedade para todos. 2. ed., Rio de Janeiro: WVA, 1997. 